Original Article

\title{
Changes of oxidative/antioxidative parameters and DNA damage in firefighters wearing personal protective equipment during treadmill walking training
}

\author{
Eunju Park, PhD ${ }^{1)^{*}}$, Yun-Jeong Lee, PhD ${ }^{1)}$, Sun-Woo Lee, PhD ${ }^{1)}$, Chang-Hoon Bang ${ }^{2}$, \\ GyuChang Lee, PT, PhD ${ }^{3)}$, Jun-Kyoung Lee, PhD ${ }^{4}$, Jung-Suk Kwan, $\mathrm{PhD}^{5}$, \\ Yu-Sub Huh, $\mathrm{PhD}^{6}$ ) \\ 1) Department of Food and Nutrition, Kyungnam University: 7 Kyungnamdaehak-ro, Masanhappo-gu, \\ Changwon-si 51767, Republic of Korea \\ 2) Department of Fire and Disaster Prevention Engineering, Kyungnam University, Republic of Korea \\ 3) Department of Physical Therapy, Kyungnam University, Republic of Korea \\ 4) Division of Mechanical Engineering, Kyungnam University, Republic of Korea \\ 5) Department of Fashion and Clothing, Kyungnam University, Republic of Korea \\ 6) Department of Physical Education, Kyungnam University, Republic of Korea
}

\begin{abstract}
Purpose] The purpose of this study was to investigate the influence of personal protective equipment on the oxidant/antioxidant parameters and DNA damage in firefighters during training and recovery. [Subjects and Methods] Twelve male nonsmoking volunteer firefighters (35.1 \pm 7.2 years) underwent two maximal treadmill training $(9 \mathrm{METs}, 6 \mathrm{~km} / \mathrm{h})$, within 2 weeks, one in regular clothes and one in personal protective equipment weighing $22.1 \mathrm{~kg}$. Blood samples were obtained before, right after, and $40 \mathrm{~min}$ after training. Plasma conjugated dienes, total radical trapping antioxidant potential, erythrocytes antioxidant enzymes activities, and leukocyte DNA damage were measured. [Results] Wearing personal protective equipment during treadmill walking training resulted in increases of plasma conjugated dienes, total radical trapping antioxidant potential, and leukocyte DNA resistance to oxidative stress, which were recovered after in $40 \mathrm{~min}$ of rest. Erythrocyte antioxidant enzymes activities remained unchanged during the training either with regular clothes or personal protective equipment. [Conclusion] These results suggest that wearing personal protective equipment during firefighting work could induce oxidative stress, which was enough to produce DNA damage in leukocytes.

Key words: Firefighter, Personal protective equipment, Walking training
\end{abstract}

(This article was submitted May 20, 2016, and was accepted Jul. 29, 2016)

\section{INTRODUCTION}

Firefighting protective clothing is designed to be put on quickly and easily by fire fighters before an emergency. Some examples of the design features of firefighting protective clothing include being fire proof and waterproof, which help protect the fire fighters wearing the protective clothing ${ }^{1)}$. However, when firefighters wear easily firefighting protective clothing, physical energy can be consumed because of the heavy weight of the firefighting protective clothing. Also, this physical exhaustion can lead to overwork and fatigue, as well as acting as the primary factor of musculoskeletal injuries ${ }^{2}$.

Fire fighters who work in a high temperature environments discharge a large amount of sweat as work strength is increased. In addition, body fluids can lead to dehydration, which can negatively affect the circulation and temperature regulation of the

*Corresponding author. Eunju Park (E-mail: pej@kyungnam.ac.kr)

(C2016 The Society of Physical Therapy Science. Published by IPEC Inc.

This is an open-access article distributed under the terms of the Creative Commons Attribution Non-Commercial No Derivatives (by-nc-nd) License $<$ http://creativecommons.org/licenses/by-nc-nd/4.0/>. 
body by intensifying the concentration of the blood ${ }^{3)}$. In addition, the body temperature rising, heat exhaustion, dehydration, heat cramps, heat exhaustion, and accompanying disorders of the central nervous system can occur due to prolonged expose to high temperatures ${ }^{4}$.

Reactive oxygen species (ROS), which are constantly formed in the human body, are suggested to contribute to pathological processes during aging and in many diseases such as diabetes, atherosclerosis, and cancer ${ }^{5)}$. Oxidative stress results when the amount of ROS exceeds the level of the antioxidant defense system, including the endogenous scavenger enzymes (superoxide dismutase, glutathione peroxidase, and catalase), and exogenous dietary antioxidants ${ }^{6}$.

Recent studies have reported the effect of wearing personal protective equipment (PPE) on physiological strain such as blood pressure (BP) and heart rate responses or maximal oxygen uptake $\left(\mathrm{VO}_{2 \max }\right)$ in firefighters ${ }^{7-9)}$. Firefighters wearing full PPE and self-contained breathing apparatus (SCBA) have exaggerated systolic BP and heart rate levels during each stage of incremental exercise, as well as during recovery time ${ }^{8)}$. Also PPE with SCBA during graded exercise treadmill have a negative impact on $\mathrm{VO}_{2 \max }$ 9).

It is well known that the metabolic challenge during physical exercise with maximal oxygen uptake results in an elevated generation of reactive oxygen species (ROS) that are important modulators of muscle contraction, antioxidant protection, and oxidative damage repair, which at moderate levels generate physiological responses ${ }^{10)}$. However, it is not completely known whether wearing PPE during training can induce oxidative stress. Thus, in this study, we investigated the oxidant/ antioxidant responses of current fire fighters wearing firefighting protective clothing while performing physical activities in an environment similar to firefighting situations.

\section{SUBJECTS AND METHODS}

The 12 subjects were firefighters recruited from a local fire station. The subjects were screened according to the following criteria: those who were 20 years of age and those who were in good health. Subjects were excluded if their cardiovascular systems were unstable, had diabetes, hypertension, or musculoskeletal or neurological diseases. Information regarding individual characteristics, health status, lifestyle factors including smoking, alcohol, and exercise habits were collected by questionnaire. The purpose and procedure of the study were explained to the subjects, and informed consent for voluntary participation was received from each. This study was performed after being approved by the Ethics Committee of Kyungnam University.

This was a single group cross-over study. All enrolled firefighters underwent two treadmill training within a 2-week period, at the same time of day: one in regular clothes (RC), and one in full firefighter PPE. The weight of PPE including firefighting protective garment $(6.6 \mathrm{~kg})$, helmet $(1.2 \mathrm{~kg})$, firefighting protective shoes $(2.9 \mathrm{~kg})$, firefighting gloves $(100 \mathrm{~g})$, and a respiratory device $(11.3 \mathrm{~kg})$ was $22.1 \mathrm{~kg}$. All trainings were performed that have 9 METs with 25 degree C for 20 min.

Dietary intake data were collected by trained interviewers using 24-hour recall method for one day before staring each test. The CAN Pro 3.0 (Korean Nutrition Society, Seoul, Korea) was used to analyze nutrient intake of the study subjects.

Polar heart rate (Sport Tester PE 3000, Polar, Finland) was used to monitor participants' exercise heart rate. Perceived exertion was measured using rating of perceived exertion $(\mathrm{RPE})^{11)}$. The scale is attached to a 10-point rating scale with 0 : very very light and 10: very very hard. Heart rate and RPE was recorded before and right after training.

Blood samples were obtained before, right after, and $40 \mathrm{~min}$ after training by venipuncture into a heparinized sterile tube, and were processed within $2 \mathrm{~h}$. Lymphocyte isolation for the comet assay was performed using the Histopaque 1077 (Sigma), followed by two washes of isolated lymphocytes with PBS. The remaining blood was centrifuged at 1,500 rpm for $30 \mathrm{~min}$ to obtain the plasma. The separated plasma was then stored at $-80{ }^{\circ} \mathrm{C}$ until further analysis of total plasma free radical levels. Erythrocytes were washed four times with PBS (pH 7.4) and were suspended in buffer for erythrocyte antioxidant enzyme analyses.

Plasma total radical-trapping antioxidant potential (TRAP) was measured after Rice-Evans and Miller's inhibition assay ${ }^{12}$, as described previously. Plasma baseline LDL conjugated diene (CD) levels were determined according to the methods outlined by Ahotupa et al. with slight modifications ${ }^{13)}$. Plasma TRAP level was calculated relative to the calibration curve of trolox and was expressed as TEAC (Trolox). The erythrocyte pellet was resuspended in ice-cold water and was processed for antioxidant enzyme activities in the separated supernatants, using a UV/VIS spectrometer. Catalase activity was measured by assessing the shrinkage of hydrogen peroxide, which was added to the erythrocyte suspension for $30 \mathrm{~s}^{14)}$. Glutathione peroxidase activitiy (GSH-Px) was determined according to the method described by Beutler ${ }^{15}$. Superoxide dismutase (SOD) activity was assayed in erythrocyte-suspension by the procedure of Marklund and Marklund ${ }^{16)}$. The reaction was monitored spectrophotometrically at $320 \mathrm{~nm}$ for $2 \mathrm{~min}$. The unit of the enzyme was defined as the amount which inhibits the autoxidation of pyrogallol by $50 \%$. DNA resistance to oxidative stress was determined by alkaline comet assay ${ }^{17)}$. The isolated leukocytes were subjected to oxidative stress by suspension in PBS with $100 \mu \mathrm{M} \mathrm{H}_{2} \mathrm{O}_{2}$. The leukocytes in agarose were added to the slides and then immersed in lysis solution $(2.5 \mathrm{M} \mathrm{NaCl}, 100 \mathrm{mM}$ EDTA, $10 \mathrm{mM}$ Tris, and $1 \%$ sodium laurylasarcosine; $1 \%$ Triton $\mathrm{X}-100$ and $10 \% \mathrm{DMSO}$ ) for $1 \mathrm{hr}$ at $4{ }^{\circ} \mathrm{C}$. For electrophoresis of the DNA, an electric current of $25 \mathrm{~V} / 300 \pm 3 \mathrm{~mA}$ was applied for $20 \mathrm{~min}$ at $4{ }^{\circ} \mathrm{C}$. Measurements were made by image analysis (Komet 4.0; Kinetic Imaging, Liverpool, UK) and fluorescence microscope (DMLB; LEICA Wetzlar, Germany). 
Table 1. Energy and antioxidant nutrients intake status in RC and PPE test

\begin{tabular}{lcc}
\hline Variables & RC test & PPE test \\
\hline Energy $(\mathrm{kcal} /$ day $)$ & $2,215.7 \pm 200.4^{\mathrm{ns}}$ & $2,084.7 \pm 174.4$ \\
Vitamin $C(\mathrm{mg} /$ day $)$ & $85.7 \pm 14.7^{\mathrm{ns}}$ & $103.1 \pm 15.9$ \\
Retinol $(\mu \mathrm{g} /$ day) & $224.0 \pm 93.7^{\mathrm{ns}}$ & $296.9 \pm 68.3$ \\
$\beta$-carotene $(\mu \mathrm{g} /$ day $)$ & $3,202.1 \pm 761.2^{\text {ns }}$ & $2,965.4 \pm 493.4$ \\
\hline
\end{tabular}

Values are means \pm SE. RC: regular clothing; PPE: personal protective equipment; ns: not significant

The values of nutrients intake were estimated by a one-day 24 -hr recall method.

Table 2. Effect of firefighting personal protective equipment on the heart rate and rating of perceived exertion during treadmill walking training

\begin{tabular}{llccc}
\hline Variables & Group & Before exercise & Right after exercise & $\begin{array}{c}\text { Changes of before } \\
\text { and after exercise }\end{array}$ \\
\hline Heart rate (beats/min) & RC test & $75.8 \pm 3.2$ & $133.3 \pm 3.6^{\# \#}$ & $57.4 \pm 4.1$ \\
& PPE test & $86.4 \pm 3.2$ & $176.6 \pm 2.7^{\# \# \#}$ & $90.2 \pm 4.6^{* * *}$ \\
Rating of & RC test & $2.5 \pm 0.5$ & $6.0 \pm 0.5^{\# \#}$ & $3.5 \pm 0.6$ \\
perceived exertion & PPE test & $3.6 \pm 0.3$ & $9.1 \pm 0.3^{\# \#}$ & $5.5 \pm 0.4^{*}$ \\
\hline
\end{tabular}

Values are means \pm SE. RC: regular clothing; PPE: personal protective equipment

\#\#\#Mean statistical differences for $\mathrm{p}<0.001$ (paired t-test) between before exercise and right after exercise.

${ }^{*},{ }^{* * *}$ Mean statistical differences for $\mathrm{p}<0.05, \mathrm{p}<0.001$ (Student $\mathrm{t}$-test) between $\mathrm{RC}$ and PPE.

Table 3. Effect of firefighting personal protective equipment on the oxidative/antioxidative parameters during treadmill walking training

\begin{tabular}{lllccc}
\hline & Variables & Group & Before exercise & Right after exercise & $\begin{array}{c}40 \text { min after } \\
\text { exercise }\end{array}$ \\
\hline Plasma & CD $(\mu \mathrm{M})$ & RC test & $5.2 \pm 0.9$ & $5.4 \pm 0.7$ & $5.3 \pm 0.6$ \\
& & PPE test & $5.5 \pm 0.8$ & $6.2 \pm 11^{\#}$ & $5.5 \pm 0.7$ \\
& TRAP $(\mathrm{mM})$ & RC test & $1.11 \pm 0.08$ & $1.11 \pm 0.11$ & $1.05 \pm 0.08$ \\
Erythrocytes & PPE test & $1.16 \pm 0.12$ & $1.24 \pm 0.10^{\# \#}$ & $1.16 \pm 0.13^{*}$ \\
& SOD & RC test & $1,632.9 \pm 64.2$ & $1,484.8 \pm 92.7$ & $1,646.5 \pm 44.3$ \\
& (U/g Hb) & PPE test & $1,688.9 \pm 58.2$ & $1,614.5 \pm 49.7$ & $1,647.1 \pm 50.8$ \\
& CAT & RC test & $110.6 \pm 5.4$ & $112.8 \pm 6.7$ & $112.6 \pm 6.5$ \\
& (Kg/g Hb) & PPE test & $109.8 \pm 6.5$ & $106.7 \pm 4.1$ & $113.5 \pm 4.5$ \\
& GPX & RC test & $26.1 \pm 3.8$ & $27.0 \pm 4.1$ & $27.9 \pm 4.0$ \\
& (U/g Hb) & PPE test & $26.7 \pm 3.0$ & $29.2 \pm 5.1$ & $23.8 \pm 3.0$ \\
& DNA damage & RC test & $83.1 \pm 1.6$ & $84.8 \pm 1.3$ & $84.0 \pm 1.4$ \\
& $(\%$ tail intensity $)$ & PPE test & $69.4 \pm 2.2$ & $82.4 \pm 1.1^{\# \# \#}$ & $77.7 \pm 1.4^{*}$ *it广 \\
\hline
\end{tabular}

Values are means \pm SE. RC: regular clothing; PPE: personal protective equipment; CD: conjugated dienes; TRAP: total radical trapping antioxidant potential; SOD: superoxide dismutase; CAT: catalase; GPX: glutathione peroxidase

$\#$ \#,\#,\#\#Mean statistical differences for $\mathrm{p}<0.05, \mathrm{p}<0.01, \mathrm{p}<0.001$ (paired t-test) between before exercise and right after exercise.

*Mean statistical differences for $\mathrm{p}<0.05$ (paired t-test) between and right after exercise and $40 \mathrm{~min}$ after exercise.

$\dagger \dagger$ Mean statistical differences for $\mathrm{p}<0.01$ (paired t-test) between before exercise and $40 \mathrm{~min}$ after exercise.

The SPSS Statistical Package, version 18.0 (IBM Inc., Chicago, IL, USA), was used for statistical analysis. Data were expressed as the mean and standard error of the mean. Statistical differences before and after trainings within groups were considered significant at $\mathrm{p}<0.05$ by paired t-test. 


\section{RESULTS}

Twelve male volunteer firefighters $(35.1 \pm 7.2$ years $)$ completed the study. The average height, weight, and BMI of the subjects were $175.4 \pm 4.3 \mathrm{~cm}, 71.8 \pm 5.9 \mathrm{~kg}$, and $23.3 \pm 1.5 \mathrm{~kg} / \mathrm{m}^{2}$ and the length of service for firefight was $7.1 \pm 6.4$ years. Ten of the subjects exercised regularly and their frequency of exercise was $4.3 \pm 0.3$ times per week.

Table 1 presents the intake status of energy and antioxidant nutrient, such as vitamin $\mathrm{C}$, retinal, and $\beta$-carotene one day before each study period and the energy intake and antioxidant nutrients intake were not significantly different between the two periods.

The physiological responses to the treadmill walking training are shown in Table 2. The treadmill walking training induced significant increases in heart rate and rating of perceived exertion either in regular clothing (RC) or in PPE. The changes of heart rate and RPE were significantly higher during the PPE test compared with the RC test.

The effect of firefighting PPE on the oxidative/antioxidative parameters during training is shown in Table 3. Plasma $\mathrm{CD}$ (an indicator for lipid peroxidation) and TRAP increased significantly during the treadmill walking training and then recovered to the baseline levels after the $40 \mathrm{~min}$ of rest in the subjects with PPE. Also, wearing PPE during training resulted in the increased of leukocyte DNA damage, which was recovered after in $40 \mathrm{~min}$ of rest, but not reached to the baseline level. Erythrocyte antioxidant enzymes activities were not affected by the training with PPE. No changes were found in of all the tested parameters in the RC group during the treadmill walking training.

\section{DISCUSSION}

In the present study, we investigated whether firefighting PPE induces oxidative stress during performing physical activities in an environment similar to firefighting situations. We found increased plasma lipid peroxidation measured by conjugated dienes level, leukocyte DNA damage measured by comet assay, and plasma total antioxidant capacity measured by TRAP assay right after the treadmill walking training with wearing PPE in healthy firefighters, while they remained unchanged during the treadmill training with wearing regular clothes.

Diene conjugation in circulating LDL used in our study is an indicator of oxidized LDL in vivo. The spectrophotometrical determination of baseline diene conjugation in LDL, which arises as an early event of lipid peroxidation reaction, is one of the important methods for monitoring LDL oxidation ${ }^{18)}$. DNA damage is known to be one of the most sensitive biological markers for evaluating oxidative stress representing the imbalance between free radical generation and deficiencies in the antioxidant system ${ }^{19,20)}$. Assessment of the total radical trapping antioxidant potential (TRAP), which is the combined capacity of all antioxidants to neutralize circulating free radicals may be a marker to signal the beginning of an oxidant antioxidant imbalance in the body fluids ${ }^{21}$. It has been reported an augmentation of conjugated dienes, DNA strand breaks, oxidative DNA damage, and total antioxidant status in human blood after a single bout of intense training ${ }^{22-25)}$. In our study, the treadmill walking training in itself for $20 \mathrm{~min}(9 \mathrm{METs}, 6 \mathrm{~km} / \mathrm{h})$ was not enough to induce oxidative stress. However, walking training with physical burden of firefighting PPE including protective garment, helmet, firefighting protective shoes, firefighting gloves, and a respiratory device $(22.1 \mathrm{~kg})$ could induce oxidative stress by increasing the generation of ROS. To the best of our knowledge, this is the first study to report oxidative stress in firefighters during activity with wearing PPE. It is postulated that the higher oxygen consumption through the self-contained breathing apparatus (SCBA) in PPE group as evidenced by the higher heart rate and rating of perceived exertion (Table 2) also contributed to elevate levels of free radicals as shown in increased levels of plasma conjugated dienes and leukocyte DNA damage. To minimize oxidative stress and remove free radicals the body uses a very effective antioxidative defense system containing exogenous antioxidants like urate, tocopherol and ascorbate and endogenous antioxidant enzymes like SOD, CAT or GPX ${ }^{26}$. Increased plasma level of TRAP might be an evidence of exertion to minimize oxidative stress induced by physical burden of PPE, whereas no contribution of the endogenous antioxidant enzymes to this redox control were found in our study.

Although the oxidative stress induced by treadmill training with PPE was restored during 40 min of recovery condition, repeated exposure to oxidative stress during firefighting might be detrimental to firefighters' health. It is reported that firefighters have one of the nation's highest occupational fatality rate in the US ${ }^{27}$ ) and the leading cause of death in firefighters is cardiac-related ${ }^{28,29)}$.

The limitation of this study was that only twelve male firefighters were included in this study, therefore, the results cannot be generalized to the entire firefighter population. Further studies can investigate the effect of PPE on oxidative/antioxidative status in other populations.

In conclusion, our study provides evidence that wearing PPE during firefighting work could induce oxidative stress, which was enough to produce DNA damage in leukocytes. Future studies are needed to understand the effect of antioxidant supplementation on oxidative stress possibly induced by firefighting work with the heavy weight of fire protection equipment to prevent the oxidative stress related diseases in firefighters.

\section{Conflict of interests}

The authors declare that they have no conflict of interests. 


\section{ACKNOWLEDGEMENT}

This research was supported by the Fire Fighting safety \& 119 Rescue Technology Research and Development Program funded by the Ministry of Public safety and Security (MEMA-NEXT GENERATION-2014-45).

\section{REFERENCES}

1) Ministry of Interior. Specification of firefighters protective clothing. 2004.

2) Walton SM, Conrad KM, Furner SE, et al.: Cause, type, and workers' compensation costs of injury to fire fighters. Am J Ind Med, 2003, 43: 454-458. [Medline] [CrossRef]

3) Heat stress control and heat casualty management. Technical bulletin Medical 507 Air Force pamphlet, 2003, 48-152(I).

4) NIOSH: Working in hot environments. NIOSH Publication, 1986, pp 86-112.

5) Waris G, Ahsan H: Reactive oxygen species: role in the development of cancer and various chronic conditions. J Carcinog, 2006, 5: 14-21. [Medline] [CrossRef]

6) Park YK, Lee SH, Park E, et al.: Changes in antioxidant status, blood pressure, and lymphocyte DNA damage from grape juice supplementation. Ann N Y Acad Sci, 2009, 1171: 385-390.

7) Lee JY, Bakri I, Kim JH, et al.: The impact of firefighter personal protective equipment and treadmill protocol on maximal oxygen uptake. J Occup Environ Hyg, 2013, 10: 397-407. [Medline] [CrossRef]

8) Feairheller DL: Blood pressure and heart rate responses in volunteer firefighters while wearing personal protective equipment. Blood Press Monit, 2015, 20: 194-198. [Medline] [CrossRef]

9) Dreger RW, Jones RL, Petersen SR: Effects of the self-contained breathing apparatus and fire protective clothing on maximal oxygen uptake. Ergonomics, 2006, 49: 911-920. [Medline] [CrossRef]

10) Radak Z, Zhao Z, Koltai E, et al.: Oxygen consumption and usage during physical exercise: the balance between oxidative stress and ROS-dependent adaptive signaling. Antioxid Redox Signal, 2013, 18: 1208-1246. [Medline] [CrossRef]

11) Morishita S, Yamauchi S, Fujisawa C, et al.: Rating of perceived exertion for quantification of the intensity of resistance exercise. Int J Phys Med Rehabil, 2013, 1: 172 .

12) Rice-Evans C, Miller NJ: Total antioxidant status in plasma and body fluids. Methods Enzymol, 1994, 234: 279-293. [Medline] [CrossRef]

13) Ahotupa M, Marniemi J, Lehtimäki T, et al.: Baseline diene conjugation in LDL lipids as a direct measure of in vivo LDL oxidation. Clin Biochem, 1998, 31: 257-261. [Medline] [CrossRef]

14) Aebi H: Methods of enzymatic analysis. Weinheim: Verlag Chemie GmbH.

15) Beutler E: Red cell metabolism: a manual for biochemical methods. Stratton: Verlag Grune, 1984, pp 71-73.

16) Marklund S, Marklund G: Involvement of the superoxide anion radical in the autoxidation of pyrogallol and a convenient assay for superoxide dismutase. Eur J Biochem, 1974, 47: 469-474. [Medline] [CrossRef]

17) Singh NP, McCoy MT, Tice RR, et al.: A simple technique for quantitation of low levels of DNA damage in individual cells. Exp Cell Res, 1988, 175: 184-191. [Medline] [CrossRef]

18) Vasankari T, Kujala U, Heinonen O, et al.: Measurement of serum lipid peroxidation during exercise using three different methods: diene conjugation, thiobarbituric acid reactive material and fluorescent chromolipids. Clin Chim Acta, 1995, 234: 63-69. [Medline] [CrossRef]

19) Kassie F, Parzefall W, Knasmüller S: Single cell gel electrophoresis assay: a new technique for human biomonitoring studies. Mutat Res, 2000 , 463: 13-31. [Medline] [CrossRef]

20) Donnelly ET, McClure N, Lewis SE: The effect of ascorbate and alpha-tocopherol supplementation in vitro on DNA integrity and hydrogen peroxide-induced DNA damage in human spermatozoa. Mutagenesis, 1999, 14: 505-512. [Medline] [CrossRef]

21) Valkonen M, Kuusi T: Spectrophotometric assay for total peroxyl radical-trapping antioxidant potential in human serum. J Lipid Res, 1997,38 : 823-833. [Medline]

22) Ramel A, Wagner KH, Elmadfa I: Plasma antioxidants and lipid oxidation after submaximal resistance exercise in men. Eur J Nutr, 2004, 43: 2-6. [Medline] [CrossRef]

23) Møller P, Loft S, Lundby C, et al.: Acute hypoxia and hypoxic exercise induce DNA strand breaks and oxidative DNA damage in humans. FASEB J, 2001, 15: 1181-1186. [Medline] [CrossRef]

24) Berzosa C, Cebrián I, Fuentes-Broto L, et al.: Acute exercise increases plasma total antioxidant status and antioxidant enzyme activities in untrained men. J Biomed Biotechnol, 2011, 2011: 540458. [Medline] [CrossRef]

25) Child RB, Wilkinson DM, Fallowfield JL, et al.: Elevated serum antioxidant capacity and plasma malondialdehyde concentration in response to a simulated half-marathon run. Med Sci Sports Exerc, 1998, 30: 1603-1607. [Medline] [CrossRef]

26) Sies H: Total antioxidant capacity: appraisal of a concept. J Nutr, 2007, 137: 1493-1495. [Medline]

27) Fabio A, Ta M, Strotmeyer S, et al.: Incident-level risk factors for firefighter injuries at structural fires. J Occup Environ Med, 2002, 44: 1059-1063. [Medline] [CrossRef]

28) Yang J, Teehan D, Farioli A, et al.: Sudden cardiac death among firefighters $\leq 45$ years of age in the United States. Am J Cardiol, 2013, 112: 1962-1967. [Medline] [CrossRef]

29) Kahn SA, Woods J, Rae L: Line of duty firefighter fatalities: an evolving trend over time. J Burn Care Res, 2015, 36: 218-224. [Medline] [CrossRef] 